\title{
Research on the influence of production fluctuation of high-production gas well on service security of tubing string
}

\author{
Zhi Zhang ${ }^{1, *}$, Jiawei Wang ${ }^{1}$, Yanjun $\mathrm{Li}^{2}$, Hexing $\mathrm{Liu}^{2}$, Wenbo Meng ${ }^{2}$, and Lei $\mathrm{Li}^{2}$ \\ ${ }^{1}$ State Key Laboratory of Oil and Gas Reservoir Geology and Exploitation (Southwest Petroleum University), Chengdu 610500, \\ PR China \\ ${ }^{2}$ CNOOC China Limited, Zhanjiang Branch, Zhanjiang 524057, China
}

Received: 7 December 2020 / Accepted: 8 June 2021

\begin{abstract}
The production of high temperature and high pressure gas wells fluctuates with time, which makes the pressure in the string fluctuate obviously and affects the service security of tubing string. In this paper, a pressure fluctuation model of the complete production process (including well opening, production and shut-in) is established, which is suitable for the multiphase flow of gas well. The pressure fluctuation in the tubing string is simulated. Influence of different well depth and average production on the fluctuating pressure of gas well are analyzed. According to the research results, if the well opening time $t_{\mathrm{op}}$ is $50 \mathrm{~s}$, a transient pressure fluctuation is generated at wellhead and drops gradually. After the production starts, a pressure fluctuation will occur at wellhead 10 15 s after $t_{\text {op }}$, which is small and attenuates quickly. Pressure increases quickly in the shut-in moment and reaches the peak at $t_{\mathrm{sh}}$. Although pressure increases gradually with the well depth, fluctuation flattens out. The hysteresis phenomenon in appearance of pressure wave becomes more and more obvious with the well depth. The greater the production of gas well, the greater the pressure fluctuation in tubing string during well opening and production, but the value may not be very high. During well shut-in, the greater the production, the greater the pressure fluctuation and the value. Amplitude, angular frequency and value of phase are in direct proportion to pressure fluctuation degree and valve radix is in inverse proportion to pressure, which means that the greater the valve radix, the smaller the pressure.
\end{abstract}

\section{Symbol annotations}

A Valve function amplitude, dimensionless

a Pressure wave velocity, $\mathrm{m} / \mathrm{s}$

$a_{\mathrm{m}} \quad$ Pressure wave velocity of multi-phase fluid, $\mathrm{m} / \mathrm{s}$

$a_{\mathrm{R}-\mathrm{K}} \quad$ The constant of R-K equation of state, dimensionless

$b_{\mathrm{R}-\mathrm{K}} \quad$ The constant of R-K equation of state, dimensionless

$B \quad$ Valve radix, dimensionless

$C_{\mathrm{g}} \quad$ Gas percentage, $\%$

$D \quad$ Diameter of tubing, $\mathrm{m}$

$E_{\mathrm{g}} \quad$ Elastic modulus of gas, $\mathrm{MPa}$

$E_{\mathrm{L}} \quad$ Elastic modulus of fluid, $\mathrm{MPa}$

$E_{\mathrm{p}} \quad$ Elastic modulus of tubing, $\mathrm{MPa}$

$F_{\text {S1 }} \quad$ Total pressure of fluid on Section $S_{1-} S_{1}$, MPa

$F_{\mathrm{S} 2} \quad$ Total pressure of fluid on Section $S_{2}-S_{2}, \mathrm{MPa}$

$F_{\mathrm{e}} \quad$ Elastic force of tubing caused by increasing section, MPa

\footnotetext{
* Corresponding author: wisezh@126.com
}

$\begin{array}{ll}\Sigma F & \text { Total external force along tubing string, MPa } \\ f & \text { Friction of tubing wall, N } \\ G_{1} & \text { Component force of gravity of controller in tubing } \\ & \text { wellbore direction, } \mathrm{N} \\ g & \text { Acceleration of gravity, } \mathrm{m} / \mathrm{s}^{2} \\ H & \text { Water head, } \mathrm{m} \\ i & \text { Number of time nodes } \\ j & \text { Hydraulic slope, m } \\ K & \text { Fluid compressibility, dimensionless } \\ k & \text { Number of position nodes } \\ l & \text { Coordinate, m } \\ \Delta l & \text { Well depth step length, m } \\ \Delta M_{1} & \text { Difference in fluid mass flowing in and out of } \mathrm{d} l \\ & \text { tubing section, kg } \\ \Delta M_{2} & \text { Increased fluid mass caused by tubing expansion } \\ & \text { and fluid compression for pressure increasing, } \mathrm{kg} \\ m & \text { Valve opening indicator, dimensionless } \\ n & \text { Valve closing indicator, dimensionless } \\ p & \text { Pressure in tubing, MPa } \\ p_{\mathrm{cr}} & \text { Critical pressure of fluid, MPa } \\ Q_{\mathrm{g}} & \text { Production of gas well, m }{ }^{3} / \text { day }\end{array}$


$R \quad$ Tubing radius, $\mathrm{m}$

$R_{\mathrm{g}} \quad$ Gas constant (it is related to the type of gas), $\mathrm{J} /(\mathrm{kg} \cdot \mathrm{K})$

$S \quad$ Cross-sectional area of tubing string, $\mathrm{m}^{2}$

$T \quad$ Temperature of fluid, $\mathrm{K}$

$T_{\text {cr }} \quad$ Critical temperature of fluid, $\mathrm{K}$

$t \quad$ Time, $\mathrm{s}$

$t_{\mathrm{op}} \quad$ Well opening time, $\mathrm{s}$

$t_{\mathrm{pr}} \quad$ Production time, $\mathrm{s}$

$t_{\mathrm{sh}} \quad$ Well shut-in time, $\mathrm{s}$

$t_{\text {en }} \quad$ End time of calculation, $\mathrm{s}$

$\Delta t \quad$ Time step length, $\mathrm{s}$

$V \quad$ Fluid velocity, $\mathrm{m} / \mathrm{s}$

$V_{\mathrm{m}} \quad$ Velocity of multi-phase flow, $\mathrm{m} / \mathrm{s}$

$v \quad$ Specific volume of gas, $\mathrm{m}^{3} / \mathrm{kg}$

$z \quad$ Position, $\mathrm{m}$

$\delta \quad$ Wall thickness of tubing, $\mathrm{m}$

$\lambda$ Coefficient of friction resistance, dimensionless

$\rho \quad$ Mean density of fluid, $\mathrm{kg} / \mathrm{m}^{3}$

$\rho_{\mathrm{m}} \quad$ Density of multi-phase fluid, $\mathrm{kg} / \mathrm{m}^{3}$

$\rho_{\mathrm{g}} \quad$ Density of gas, $\mathrm{kg} / \mathrm{m}^{3}$

$\rho_{1} \quad$ Density of liquid, $\mathrm{kg} / \mathrm{m}^{3}$

$\theta \quad$ Angle between the tubing axis and horizontal, $\left(^{\circ}\right)$

$\gamma \quad$ Volume-weight, $\mathrm{N} / \mathrm{m}^{3}$

$\sigma \quad$ Stress of tubing, $\mathrm{MPa}$

$\beta \quad$ Weighted coefficients of diffused difference schemes, dimensionless

$\tau(t) \quad$ Valve function, dimensionless

$\omega \quad$ Wave angular frequency, $\mathrm{rad} / \mathrm{s}$

$\varphi \quad$ Phase angle, rad.

\section{Introduction}

There are abundant natural gas resources of onshore deep layer in China. According to the 4th evaluation results of oil and gas resources of China National Petroleum Corporation $(C N P C)$, the quantity of resources in ultra-deep formation of onshore is $42 \%$ of the total quantity of conventional natural gas resources. Therefore most of the wells are ultra-deep (the deepest onshore oil well in Asia, Luntan Well 1 is $8882 \mathrm{~m}$, the deepest onshore horizontal well, Shuangyu Well X133 is $8102 \mathrm{~m}$ ), ultra-temperature (Tatan Well 1 is $200{ }^{\circ} \mathrm{C}$ ) and ultra-high pressure (Longgang Well 70 is $160 \mathrm{MPa}$ ) (Wu et al., 2020). With the development of these high-temperature, high-pressure and high-production oil and gas wells, the difficulty of oil and gas exploration is increasing, which puts forward higher requirements for wellbore integrity (Zhang et al., 2017a, 2018, 2019).

During exploitation of high-temperature, high-pressure and high-production gas wells, fluid flow rate in tubing string is high. In addition to well opening and shut-in conditions (Han et al., 2012; Jin et al., 2011), the different geological conditions of different regions will affect the production of gas well (Zhang et al., 2020a). If the fluid flow rate in tubing string changes significantly for certain factors and results in momentum conversion in these conditions, violent pressure fluctuations will be caused in tubing string (Li et al., 2013). Obvious fluctuation amplitude and large pressure value will threaten the service security of tubing string and cause serious wellbore integrity problems (Zhang et al., 2013, 2017b), which may have big impact on field operation safety. Therefore, it is very important to study the transient flow process and pressure fluctuation in tubing string during the complete production process of gas well to ensure the wellbore integrity and safe production of gas well (Zhang et al., 2020b).

\section{Research status of pressure fluctuation in tubing of gas well}

As gas well is filled with high-pressure natural gas mixed fluid, the action of wellhead valve or production fluctuation may force a change in the flow pattern of natural gas near the wellhead, creating a fluctuating pressure that is transmitted in tubing string. The pressure fluctuation in the tubing string caused by the change of valve state shows the compressibility of fluid, which is a typical transient flow problem (Bojan et al., 2018). It reflects that all the physical quantities of motion (velocity, acceleration, pressure, density, etc.) in the basin have both time-varying and locationvarying properties during the fluid movement process. Menabrea, Joukowsky (1904), Allievi (1925), and other scholars have successively carried out relevant studies on the hydraulic transient problem. From deriving the pressure wave velocity formula to the calculation of direct water hammer and indirect water hammer, the hydraulic transient problem has gradually become a major research topic in the field of fluid mechanics. American scientist, Professor Streeter, composed the Transient Flow (Wylie and Streeter, 1983) according to the research results of hydraulic transient, which was one of the most iconic work introducing hydraulic transient problems. Method Of Characteristics (short for MOC), which is widely used to solve hydraulic transient problem, was first proposed in Transient Flow.

The process of pressure fluctuation in tubing string of gas well has been studied in different degrees by several scholars. Ogunyemi and Oghenewoakpo (2019) studied the impact of pressure fluctuation caused by "water hammer" on stratum during well shut-in process. According to the results, soft shut-in procedure allows additional well penetration, and increases the stratum pressure. But hard shut-in procedure reduces additional well penetration and decreases the possibility of formation fracture. Assaad et al. (2019) proposed a model to simulate the surge pressure and pressure wave propagation during oil and gas well construction. Adiputro et al. (2020) applied numerical Pressure Transient Analysis (PTA) to well MOL-GT-03, Belgium, using one dimensional radial model with fractional dimension grid gave a good match with field data clearly indicating low reservoir permeability and the fractured nature of the reservoir. In addition, the water hammer effect was investigated by solving the wave equation to help identifying the extent of the well reach providing an estimate to the reservoir boundary. Lin et al. (2018) put forward the drawing method of the water hammer wave 
velocity standard chart by analyzing the influences of the main parameters on the water hammer wave velocity, and the water hammer wave velocity standard chart was drawn. This chart can be used to query the water hammer wave velocity of the wellbore gas-liquid two-phase flow under different temperature, pressure and water content. Fang et al. (2019) aim at the problem of wellbore gas encountering high-pressure formation gas could bring substantial risks in gas drilling process. A theoretical model for pressure wave velocity and attenuation coefficient in gaseous phase flow is established and analytically solved by classic fluid-mechanics model and small perturbation theory. To analyze the fracture characteristics of tubing, Mou et al. (2019) carried out experimental study on the fracture surface of tubing and established finite elements model of water hammer effect to calculate pressure variation in tubing. Zhang et al. (2020c) established mathematical model of multiphase fluid gas well transient flow based on mechanism of water hammer effect and theory of multiphase flow, divided the deflecting section of tubing string into several parts and realized the analog computation of transient flow in tubing string after gas well shut-in.

Many scholars have made elaborations on the pressure variation in tubing string of gas well in different degrees, but the report on the pressure fluctuation in tubing string of gas well during complete production process is still insufficient. In this paper, a pressure fluctuation model of the complete production process (including well opening, production and shut-in) is established, which is suitable for the multiphase flow of gas well. The pressure fluctuation in the tubing string is simulated. Influence of different well depth and average production on the fluctuating pressure of gas well are analyzed.

\section{Research on the influence of production fluctuation on fluctuating pressure and service security of tubing}

Due to the different geological conditions of different regions and other factors during the production of oil and gas well, the production will fluctuate with time. The fluctuation of production will lead to the change of fluid pressure and flow rate in the tubing, and great changes will affect the tubing string in varying degrees. For example, the oil pressure fluctuation may result in a pressure difference in tubing string and the change of fluid velocity may generate a huge impact load on tubing string, which will cause pressure disturbance in the tubing. Figure 1 shows the fluctuating of wellhead oil pressure of a gas well in Western China during production.

In addition, oil and gas well also faces the working conditions of well opening and shut-in. If the fluid flow rate in tubing string changes significantly all of a sudden in these conditions, violent pressure fluctuations will be caused in tubing string. At present, related research data on this problem are insufficient. It is of great importance to establish corresponding model, make analysis on it and put it into field applications for guaranteeing service security of tubing string and wellbore integrity.

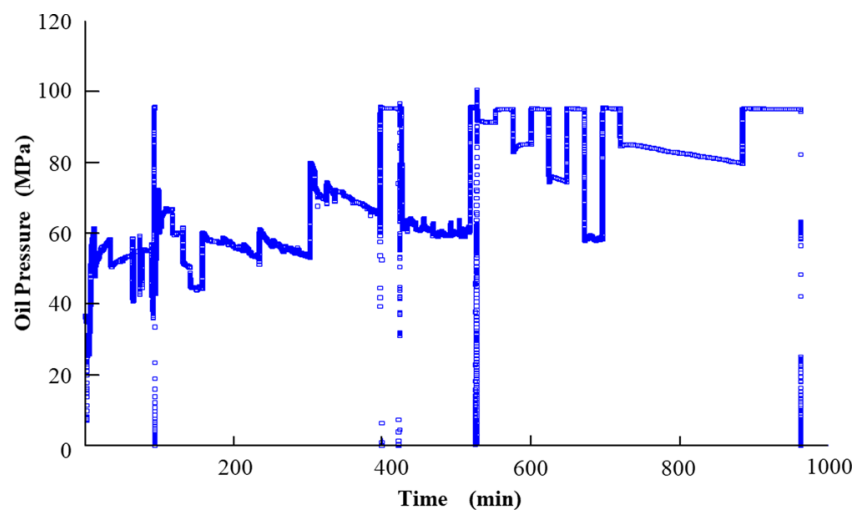

Fig. 1. The fluctuating of wellhead oil pressure of a gas well in Western China during production.

\subsection{Force analysis for fluid micro-element in tubing}

The theory of pressure fluctuation in the gas well can be derived from the theory of transient flow in the pipeline and factors those have not been considered in the flow of single-phase fluid in horizontal pipeline, such as gravity term of vertical tubing and multi-phase flow, etc. shall be taken into consideration. The hydraulic transient process in the pipeline is described based on basic differential equation of water hammer, composed of motion equation and continuity equation. It is a mathematical expression to comprehensively express the law of unsteady flow in pressure pipeline flow and a form of one-dimensional wave equation.

Flowing process of fluid in gas well is similar with the water flow in pipeline. By deriving the hydraulic transient process in pipeline, considering the influence of gravity acceleration and multi-phase fluid on tubing flow, the pressure variation in the tubing in a complete production process of the gas well is simulated. As the subsurface environment is complicated and changeable, it is necessary to idealize the model: 1) The flow in the pipe is one-dimensional, and the multiphase fluid along the same section of the pipe is distributed uniformly and the flow rate is the same; 2) regardless of the bending deflection of pipeline, assuming that pipeline is composed of elastic materials; 3 ) the formula in constant flow is still used to analyze the friction resistance in transient flow.

\subsection{Motion equation}

The stress analysis of fluid micro elements in the pipe is shown in Figure 2 and Table 1. According to the Newton's second law of motion, the external force on the control volume is equal to the mass of the control volume multiplied by the motion acceleration. Direction of acceleration is the direction of total external force. Therefore, the total external force along the pipeline axis is

$$
\begin{aligned}
& \Sigma F=\gamma S(H-z)-\gamma\left(S+\frac{\delta S}{\delta l} \mathrm{~d} l\right)\left(H-z+\frac{\delta H}{\delta l} \mathrm{~d} l+\sin \theta \mathrm{d} l\right) \\
& +\gamma\left(S+\frac{\delta S}{\delta l} \frac{\mathrm{d} l}{2}\right) \sin \theta \mathrm{d} l+\gamma\left(H-z+\frac{\delta H}{\delta l} \frac{\mathrm{d} l}{2}+\frac{\mathrm{d} l}{2} \sin \theta\right) \frac{\delta S}{\delta l} \mathrm{~d} l \\
& -\pi D \mathrm{~d} l \sigma .
\end{aligned}
$$


In the above equation, the positive direction of the force is the direction of the fluid flowing to the valve section of the pipeline. By expanding the above formula and omitting the high-order term, the resultant force along the axial direction of the pipe is obtained as follow

$$
\Sigma F=-\mathrm{d} l\left(\gamma S \frac{\delta H}{\delta l}+\pi D \sigma\right) .
$$

As the mass of micro-fluid is $\frac{\gamma S \mathrm{~d} l}{g}$, acceleration is $\frac{\mathrm{d} V}{d t}$, it can be obtained according to the Newton's second law of motion

$$
-\mathrm{d} l\left(\gamma S \frac{\delta H}{\delta l}+\pi D \sigma\right)=\frac{\gamma S \mathrm{~d} l}{g} \frac{\mathrm{d} V}{d t} .
$$

If $R$ is the radius of pipeline, $J$ is the hydraulic slope (namely frictional resistance loss), there is $\pi D \sigma=$ $\pi \times 2 R \gamma \times(R / 2) \times J=S \gamma J$, take it into equation (3) to eliminate, it can be obtained that

$$
\frac{\delta H}{\delta l}+\frac{1}{g} \frac{\mathrm{d} V}{d t}+J=0 .
$$

Flow rate $V$ is the function of coordinate in tubing flow $l$ and time $t$, namely $V=V(l, t)$. For the convenience of integrating, $\frac{\mathrm{d} V}{d t}$ can be expanded by total differential definition

$$
\frac{\mathrm{d} V}{d t}=\frac{\delta V}{\delta t}+\frac{\delta V}{\delta l} \frac{\mathrm{d} l}{d t}=\frac{\delta V}{\delta t}+V \frac{\delta V}{\delta l} .
$$

Therefore, equation (4) can be written as

$$
\frac{\delta H}{\delta l}+\frac{1}{g}\left(\frac{\delta V}{\delta t}+V \frac{\delta V}{\delta l}\right)+J=0 .
$$

Hydraulic slope $J=\frac{\lambda}{D} \frac{V|V|}{2 g}$, after taking it into equation (6), the equation of motion for hydraulic transient process can be obtained as follow

$$
\frac{\delta H}{\delta l}+\frac{1}{g} \frac{\delta V}{\delta t}+\frac{V}{g} \frac{\delta V}{\delta l}+\frac{\lambda}{D} \frac{V|V|}{2 g}=0 .
$$

Convert water head into pressure, then equation (7) can be written as

$$
\frac{1}{\rho} \frac{\delta P}{\delta l}+\frac{\delta V}{\delta t}+V \frac{\delta V}{\delta l}+\frac{\lambda V|V|}{2 D}=0 .
$$

In the derivation of the equation, the gravity term of pipe flow is taken into account, and the elasticity of pipe wall is not involved. Therefore, the equation is applicable to vertical pipes and varying diameter pipes, as well as inclined pipes and pipes of different materials.

\subsection{Continuity equation}

Whether laminar state or hydraulic transient state, continuity condition is the basic condition of the model of pressurized pipe flow. According to law of conservation of mass, the mass difference of fluid $\Delta M_{1}$ flowing in and out of $\mathrm{d} l$ tubing section shall equal to the increased mass of fluid $\Delta M_{2}$ caused by the expansion of casing wall and fluid compression in the time interval of $\mathrm{d} t$.
Assuming that the cross-sectional area at B is $S$, flow rate is $V$ and average density of fluid is $\rho$, there is

$$
\Delta M_{1}=\rho S V \mathrm{~d} t-\left(\rho+\frac{\delta \rho}{\delta l} \mathrm{~d} l\right)\left(S+\frac{\delta S}{\delta l} \mathrm{~d} l\right)\left(V+\frac{\delta V}{\delta l} \mathrm{~d} l\right) \mathrm{d} t .
$$

By expanding the above formula and omitting the highorder term

$$
\Delta M_{1}=-\mathrm{d} l \mathrm{~d} t\left(V \rho \frac{\delta S}{\delta l}+S V \frac{\delta \rho}{\delta l}+S \rho \frac{\delta V}{\delta l}\right) .
$$

Besides

$$
\Delta M_{2}=\frac{\mathrm{d}}{\mathrm{d} t}(\rho S V \mathrm{~d} l) \mathrm{d} t=\mathrm{d} l \mathrm{~d} t\left(\rho \frac{\mathrm{d} S}{\mathrm{~d} t}+S \frac{\mathrm{d} \rho}{\mathrm{d} l}\right) .
$$

As $\Delta M_{1}=\Delta M_{2}$, there is

$$
-\mathrm{d} l \mathrm{~d} t\left(V \rho \frac{\delta S}{\delta l}+S V \frac{\delta \rho}{\delta l}+S \rho \frac{\delta V}{\delta l}\right)=\mathrm{d} l \mathrm{~d} t\left(\rho \frac{\mathrm{d} S}{\mathrm{~d} t}+S \frac{\mathrm{d} \rho}{\mathrm{d} l}\right) .
$$

Eliminate $\frac{\mathrm{d} l}{\mathrm{~d} t}$. As $\frac{\delta S}{\delta l}$ and $\frac{\delta \rho}{\delta l}$ are much smaller than $\frac{\delta V}{\delta l}$, which can be ignored, there is

$$
-S \rho \frac{\delta V}{\delta l}=\rho \frac{\mathrm{d} S}{\mathrm{~d} t}+S \frac{\mathrm{d} \rho}{\mathrm{d} t} .
$$

Namely

$$
-\frac{\delta V}{\delta l}=\frac{1}{S} \frac{\mathrm{d} S}{\mathrm{~d} P} \frac{\mathrm{d} P}{\mathrm{~d} t}+\frac{1}{\rho} \frac{\mathrm{d} \rho}{\mathrm{d} P} \frac{\mathrm{d} P}{\mathrm{~d} t} .
$$

After a simple conversion, it can be obtained that

$$
-\frac{\delta V}{\delta l}=\frac{\mathrm{d} P}{\mathrm{~d} t}\left(\frac{1}{S} \frac{\mathrm{d} S}{\mathrm{~d} P}+\frac{1}{\rho} \frac{\mathrm{d} \rho}{\mathrm{d} P}\right) .
$$

As pressure wave speed $a$ is identified as

$$
a=\frac{1}{\sqrt{\rho\left(\frac{1}{S} \frac{\mathrm{d} S}{\mathrm{~d} P}+\frac{1}{\rho} \frac{\mathrm{d} \rho}{\mathrm{d} P}\right)}} .
$$

Equation (15) can be written as

$$
-\frac{\delta V}{\delta l}=\frac{\mathrm{d} P}{\mathrm{~d} t} \frac{1}{\rho a^{2}} .
$$

By expanding the above formula and obtain that

$$
-\frac{\delta V}{\delta l}=\frac{1}{\rho a^{2}}\left(\frac{\delta P}{\delta t}+V \frac{\delta P}{\delta l}\right) .
$$

As $=\frac{P}{\gamma}+z$, take the partial derivative of $H$ to $t$

$$
\frac{\delta H}{\delta t}=\frac{1}{\gamma} \frac{\delta P}{\delta t}+\frac{\delta z}{\delta l} .
$$

As $\frac{\delta z}{\delta l}=0$, there is

$$
\frac{\delta P}{\delta t}=\gamma \frac{\delta H}{\delta t}
$$


Then take the partial derivative of $H$ to $l$, there is

$$
\frac{\delta P}{\delta l}=\gamma \frac{\delta H}{\delta l}-\gamma \frac{\delta z}{\delta l}
$$

Take equations (20) and (21) into equation (18), there is

$$
-\frac{a^{2}}{g} \frac{\delta V}{\delta l}=\frac{\delta H}{\delta t}+V\left(\frac{\delta H}{\delta l}-\frac{\delta z}{\delta l}\right) .
$$

In the above equation, $\frac{\delta z}{\delta l}=\frac{\mathrm{d} z}{\mathrm{~d} l}=-\sin \theta$, take it back into equation (22), the continuity equation of hydraulic transient process can be obtained as follow

$$
\frac{\delta H}{\delta t}+V\left(\frac{\delta H}{\delta l} \sin \theta\right)+\frac{a^{2}}{g} \frac{\delta V}{\delta l}=0 .
$$

Convert water head into pressure, then equation (23) can be written as

$$
\frac{\delta P}{\delta t}+V \frac{\delta P}{\delta l}+\rho a^{2} \frac{\delta V}{\delta l}+\rho a^{2} V \sin \theta=0 .
$$

Both motion equation and continuity equation reflect the change rule of flow rate and pressure in the process of hydraulic transient in the form of partial differential equation, which provide basic theoretical formulas for solving the problems of transient flow calculation.

\subsection{Pressure wave velocity of multi-phase flow}

In the process of calculation, the pressure wave velocity $a$ is a very important intermediate variable and its algebraic analytic expression shall be obtained by deforming its equation of definition. Here, the elasticity of the pipe wall needs to be considered. For the pipe with the diameter of $D$ and cross-sectional area of $S$, pipe wall expands when the increase of fluid pressure in pipe is $\mathrm{d} P$, the increase of pipe diameter is $\mathrm{d} D$, and the corresponding increase of cross-sectional area is $\mathrm{d} S=\mathrm{d}\left(\frac{\pi}{4} D^{2}\right)=\frac{\pi}{2} D \mathrm{~d} D$, then there is

$$
\frac{1}{S} \frac{\mathrm{d} S}{\mathrm{~d} P}=\frac{1}{\mathrm{~d} P} \frac{\mathrm{d} S}{S}=\frac{\frac{\pi}{2} D \mathrm{~d} D}{\frac{\pi}{4} D^{2}} \frac{1}{\mathrm{~d} P}=\frac{2 \mathrm{~d} D}{D} \frac{1}{\mathrm{~d} P} .
$$

According to Hooke's law, the relationship between the increase of pipe diameter $\mathrm{d} D$ and the increase of pipe wall stress $\mathrm{d} \sigma$ is

$$
\frac{\mathrm{d} D}{D}=\frac{d \sigma}{E_{\mathrm{p}}},
$$

wherein, $\sigma$ is the stress of pipe wall, and $E_{\mathrm{p}}$ is the elastic modulus of the pipe wall. For pipeline with the wall thickness of $\delta$, its stress is

$$
\sigma=\frac{P D}{2 \delta}
$$

Thus,

$$
d \sigma=\frac{D}{2 \delta} \mathrm{d} P .
$$

Take equations (26) and (28) into equation (25), it can be obtained that

$$
\frac{1}{S}=\frac{\mathrm{d} S}{\mathrm{~d} P}=\frac{D}{E_{\mathrm{p}} \delta} .
$$

Then according to the compressibility of fluid, there is

$$
\frac{1}{\rho} \frac{\mathrm{d} \rho}{\mathrm{d} P}=\frac{1}{K} .
$$

So the pressure wave velocity can be written as

$$
a=\frac{1}{\sqrt{\rho\left(\frac{1}{K}+\frac{D}{E_{\mathrm{p}} \delta}\right)}}=\sqrt{\frac{K}{\rho}} \frac{1}{\sqrt{1+\frac{K D}{E_{\mathrm{p}} \delta}}} .
$$

From equation (31), it can be known that as the value of $\frac{1}{\sqrt{1+\frac{K D}{E_{\mathrm{p} \delta}}}}$ is smaller than 1 , the pressure wave velocity value after taking elasticity of pipe wall into consideration shall be smaller than the value not taking elasticity of pipe wall into consideration, and the increase of water hammer pressure is smaller under the same factors. The greater the pipe diameter $D$, the smaller the pressure wave velocity and the smaller the increase of water hammer pressure. The thicker the pipe wall, the greater the pressure wave velocity and the greater the increase of water hammer pressure. Therefore, flexible pipe with large diameter and thin wall is beneficial to reduce water hammer pressure.

According to the analytical form (31) of pressure wave velocity of single-phase flow, $a_{\mathrm{m}}$ can be identified as follow when multi-phase flow factor is taken into consideration

$$
a_{\mathrm{m}}=\sqrt{\frac{1}{\rho_{\mathrm{m}}\left[\left(\frac{1}{E_{\mathrm{L}}}\left(1-C_{\mathrm{g}}\right)+\frac{1}{E_{\mathrm{g}}} C_{\mathrm{g}}\right) \frac{D}{E_{\mathrm{p}} \delta}\right]}} .
$$

According to (32), the pressure wave velocity of multi-phase fluid has connections with gas percentage $C_{\mathrm{g}}$, elastic modulus of gas $E_{\mathrm{g}}$, elastic modulus of liquid $E_{\mathrm{L}}$, density of multiphase mixture $\rho_{\mathrm{m}}$, elastic modulus of tubing wall $E_{\mathrm{p}}$ and wellbore size $D$ and $\delta$.

\subsection{Calculation of fluid state in tubing}

According to the assumption of the previous model, the elastic modulus of the fluid is constant. Therefore, the pressure wave velocity of multiphase flow is only related to the density of multiphase $\rho_{\mathrm{m}}$.

Density of multiphase $\rho_{\mathrm{m}}$ can be defined as formula (33)

$$
\rho_{\mathrm{m}}=C_{\mathrm{g}} \rho_{\mathrm{g}}+\left(1-C_{\mathrm{m}}\right) \rho_{1} .
$$

For high production gas wells, a small amount of water will be produced, but the water content is tiny. So it is assumed that the flow is homogeneous, and the percentage of gas $C_{\mathrm{g}}$ can be obtained by the ratio of natural gas production to total flow.

Because of the high pressure and strong compressibility of the natural gas in the tubing, the calculation of the density of the natural gas cannot be realized simply by the state equation of the ideal gas. At present, there are mainly van der Waals equation and $\mathrm{R}-\mathrm{K}$ equation to calculate 
the actual state of natural gas, in which the accuracy of R$\mathrm{K}$ equation is higher.

The $\mathrm{R}-\mathrm{K}$ equation of state is based on van der Waals equation, and its accuracy is much higher than the former, especially for the calculation of gas-liquid equilibrium and mixture. The specific form of the equation is

$$
p=\frac{R_{\mathrm{g}} T}{v-b_{\mathrm{R}-\mathrm{K}}}-\frac{a_{\mathrm{R}-\mathrm{K}}}{T^{\frac{1}{2}} v\left(v-b_{\mathrm{R}-\mathrm{K}}\right)} .
$$

where $a_{\mathrm{R}-\mathrm{K}}$ and $b_{\mathrm{R}-\mathrm{K}}$ are the constants of R-K equation of state, usually obtained from the experimental data of $p, v$ and $T$. They can also be calculated by the critical point parameters.

$$
\begin{aligned}
a_{\mathrm{R}-\mathrm{K}} & =\frac{0.42748 R_{\mathrm{g}}^{2} T_{\mathrm{cr}}^{\frac{5}{2}}}{P_{\mathrm{cr}}} . \\
b_{\mathrm{R}-\mathrm{K}} & =\frac{0.08664 R_{\mathrm{g}} T_{\mathrm{cr}}}{P_{\mathrm{cr}}} .
\end{aligned}
$$

By transforming the R-K equation, the cubic equation with the gas specific volume $v$ as the main unknown can be obtained

$$
v^{3}-X_{1} v^{2}-X_{2} v-X_{3}=0
$$

wherein,

$$
\left\{\begin{array}{l}
X_{1}=\frac{R_{\mathrm{g}} T}{p} \\
X_{2}=a_{\mathrm{R}-\mathrm{K}}^{2}+\frac{R_{\mathrm{g}} T b_{\mathrm{R}-\mathrm{K}}}{p}-\frac{b_{\mathrm{R}-\mathrm{K}}}{p T^{\frac{1}{2}}} . \\
X_{3}=\frac{a_{\mathrm{R}-\mathrm{K}} b_{\mathrm{R}-\mathrm{K}}}{p T^{\frac{1}{2}}}
\end{array}\right.
$$

Since the specific volume and density of the gas are reciprocal to each other, the following formula can be obtained

$$
\left(\frac{1}{\rho_{\mathrm{g}}}\right)^{3}-X_{1}\left(\frac{1}{\rho_{\mathrm{g}}}\right)^{2}-X_{2}\left(\frac{1}{\rho_{\mathrm{g}}}\right)^{3}-X_{3}=0 .
$$

In conclusion, the density of gas is a function of $T$ and $p$. The temperature and pressure of fluid in tubing change along the direction of well depth, so the mixture density also changes. There is no instantaneous high-energy process such as explosion in the tubing, so the liquid density is regarded as constant.

In addition, the velocity of multi-phase flow $V_{\mathrm{m}}$ is calculated according to the formula of gas-liquid mixture velocity. That is, the ratio of total volume flow to crosssectional area

$$
V_{\mathrm{m}}=\frac{Q_{\mathrm{g}}+Q_{l}}{S}
$$

wherein, $Q_{\mathrm{g}}$ is the gas flow and $Q_{1}$ is the liquid flow (water production rate). The value of gas production cannot be directly substituted into formula (40), and it needs to be converted by gas state equation.

\section{Numerical solutions and boundary conditions of model}

\subsection{Explicit difference solution}

If an actual problem is abstracted as a mathematical problem and the actual process is regarded as a continuous solution area, then the explicit difference method is to mesh the continuous solution area, and one or more objective functions of the problem can be approximated as variable functions that are discretized on the grid node (Sun et al., 2019). The technological difficulty of explicit difference is how to divide the solution region according to the characteristics of concrete issues and how to discretize the original differential equation into system of difference equation and solve the algebraic equations.

In order to solve the model, it is necessary to discretize the basic equation and convert the differential equation into difference algebraic equation. Here, the diffusion difference scheme is used to solve the equation. The objective function pressure $P$ or velocity $V$ is represented by $X$, set the time node $i$, position node $k$, the partial differential of $X$ to time and position can be expressed as

$$
\begin{gathered}
\frac{\delta X}{\delta t}=\frac{X_{i}^{k}-\left[\beta X_{i}^{k}+\frac{1-\beta}{2}\left(X_{i+1}^{k-1}+X_{i-1}^{k-1}\right)\right]}{\Delta t}, \\
\frac{\delta X}{\delta l}=\frac{X_{i+1}^{k-1}+X_{i-1}^{k-1}}{2 \Delta l} .
\end{gathered}
$$

Following differential equations can be obtained by taking equations (41) and (42) into hydraulic transient basic equation

$$
\begin{gathered}
\frac{p_{i}^{k}-\left[\beta p_{i}^{k-1}+\frac{1-\beta}{2}\left(p_{i+1}^{k-1}+p_{i-1}^{k-1}\right)\right]}{\Delta t}+V_{i}^{k-1} \frac{p_{i+1}^{k-1}+p_{i-1}^{k-1}}{2 \Delta l} \\
-\rho_{\mathrm{m}} g V_{i}^{k-1} \sin \theta+\rho_{\mathrm{m}} a^{2} \frac{V_{i+1}^{k-1}+V_{i-1}^{k-1}}{2 \Delta l}=0, \\
\frac{V_{i}^{k}-\left[\beta V_{i}^{k-1}+\frac{1-\beta}{2}\left(V_{i+1}^{k-1}+V_{i-1}^{k-1}\right)\right]}{\Delta t}+\frac{1}{\rho_{\mathrm{m}}} \frac{p_{i+1}^{k-1}+p_{i-1}^{k-1}}{2 \Delta l} \\
+V_{i}^{k-1} \frac{V_{i+1}^{k-1}+V_{i-1}^{k-1}}{2 \Delta l}+\frac{\lambda}{2 D} V_{i}^{k-1}\left|V_{i}^{k-1}\right|=0 .
\end{gathered}
$$

It can be simplified as

$$
\begin{aligned}
p_{i}^{k}= & {\left[\beta p_{i}^{k-1}+\frac{1-\beta}{2}\left(p_{i+1}^{k-1}+p_{i-1}^{k-1}\right)\right]-V_{i}^{k-1} \frac{p_{i+1}^{k-1}+p_{i-1}^{k-1}}{2 \Delta l} \Delta t } \\
& +\rho_{\mathrm{m}} g V_{i}^{k-1} \sin \theta \Delta t+\rho_{\mathrm{m}} a^{2} \frac{V_{i+1}^{k-1}+V_{i-1}^{k-1}}{2 \Delta t} \Delta, \\
V_{i}^{k}= & {\left[\beta V_{i}^{k-1}+\frac{1-\beta}{2}\left(V_{i+1}^{k-1}+V_{i-1}^{k-1}\right)\right]-\frac{1}{\rho_{\mathrm{m}}} \frac{p_{i+1}^{k-1}+p_{i-1}^{k-1}}{2 \Delta l} \Delta t } \\
& -V_{i}^{k-1} \frac{V_{i+1}^{k-1}+V_{i-1}^{k-1}}{2 \Delta l} \Delta t-\frac{\lambda}{2 D} V_{i}^{k-1}\left|V_{i}^{k-1}\right| .
\end{aligned}
$$


Table 1. Force analysis for fluid micro-element in tubing.

\begin{tabular}{|c|c|c|c|}
\hline $\mathrm{S} / \mathrm{N}$ & Name and Symbol & Expression & Orientation \\
\hline 1 & $\begin{array}{l}\text { Total pressure of fluid on Section } \\
\mathrm{S}_{1}-\mathrm{S}_{1}, F_{\mathrm{S} 1}\end{array}$ & $\gamma S(H-z)$ & $\begin{array}{l}\text { Pointing to the direction of the } \\
\text { downstream and along the } \\
\text { pipeline axis }\end{array}$ \\
\hline 2 & $\begin{array}{l}\text { Total pressure of fluid on Section } \\
\mathrm{S}_{2}-\mathrm{S}_{2}, F_{\mathrm{S} 2}\end{array}$ & $\gamma\left(S \frac{\delta S}{\delta l}+\mathrm{d} l\right)\left(H-z+\frac{\delta H}{\delta l}+\mathrm{d} l+\sin \theta \mathrm{d} l\right)$ & In contrast to $F_{\mathrm{S} 1}$ \\
\hline 3 & $\begin{array}{l}\text { Component force of weight control } \\
\text { along tubing axis } G_{1}\end{array}$ & $\gamma\left(S+\frac{\delta S}{\delta l} \frac{\mathrm{d} l}{2}\right) \sin \theta \mathrm{d} l$ & Same as $F_{\mathrm{S} 1}$ \\
\hline 4 & $\begin{array}{l}\text { Elastic force of casing wall caused by } \\
\text { the expanding of cross section } F_{\mathrm{e}}\end{array}$ & $\gamma\left(H-z+\frac{\delta H}{\delta l} \frac{\mathrm{d} l}{2}+\frac{\mathrm{d} l}{2} \sin \theta\right) \frac{\delta S}{\delta l} \mathrm{~d} l$ & Same as $F_{\mathrm{S} 1}$ \\
\hline 5 & Friction of casing wall $f$ & $\pi D \mathrm{~d} l \sigma$ & In contrast to $F_{\mathrm{S} 1}$ \\
\hline
\end{tabular}

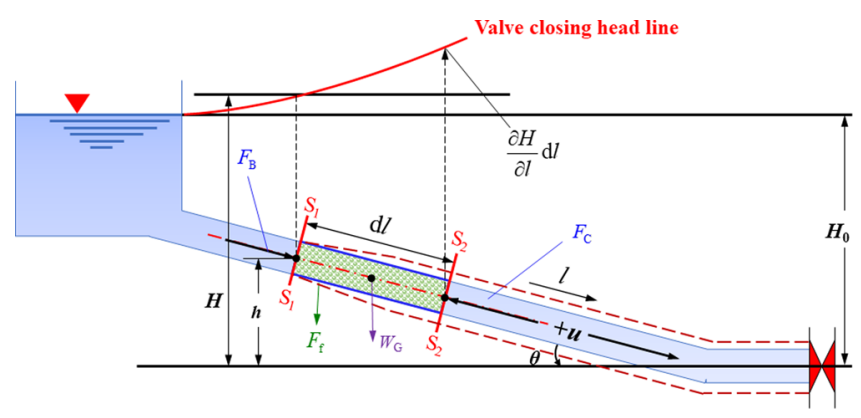

Fig. 2. Force analysis for fluid micro-element in tubing.

According to equations (45) and (46), if the pressure $p_{i-1}$ and flow rate $V_{i-1}$ on every grid node at the time of $i-1$ are known, then the pressure $p_{i}$ and flow rate $V_{i}$ on every grid node at the time of $i$ can be obtained successively by taking the known values into equation.

\subsection{Boundary conditions of valve}

The complete production process includes three kinds of working conditions: well opening, production and shut-in. It is easy to obtain the wellhead valve function of well opening and shut-in. If only well opening or shut-in operations are needed, and the well opening time is $t_{\mathrm{op}}$, well shut-in time is $t_{\mathrm{sh}}$, valve opening indicator is $m$ and valve closing indicator is $n$, there is

$$
\begin{gathered}
\tau(t)=\left\{\begin{array}{l}
\left(\frac{t}{t_{\mathrm{op}}}\right)^{m}, \quad t \leq t_{\mathrm{op}} \\
1, \quad t>t_{\mathrm{op}}
\end{array}\right. \\
\tau(t)= \begin{cases}\left(1-\frac{t}{t_{\mathrm{sh}}}\right)^{n}, & t \leq t_{\mathrm{sh}} \\
0, & t>t_{\mathrm{sh}}\end{cases}
\end{gathered}
$$

During natural gas exploitation, the production of natural gas is actually in fluctuation situation. The stimulation of production fluctuation will induce the pressure fluctuation

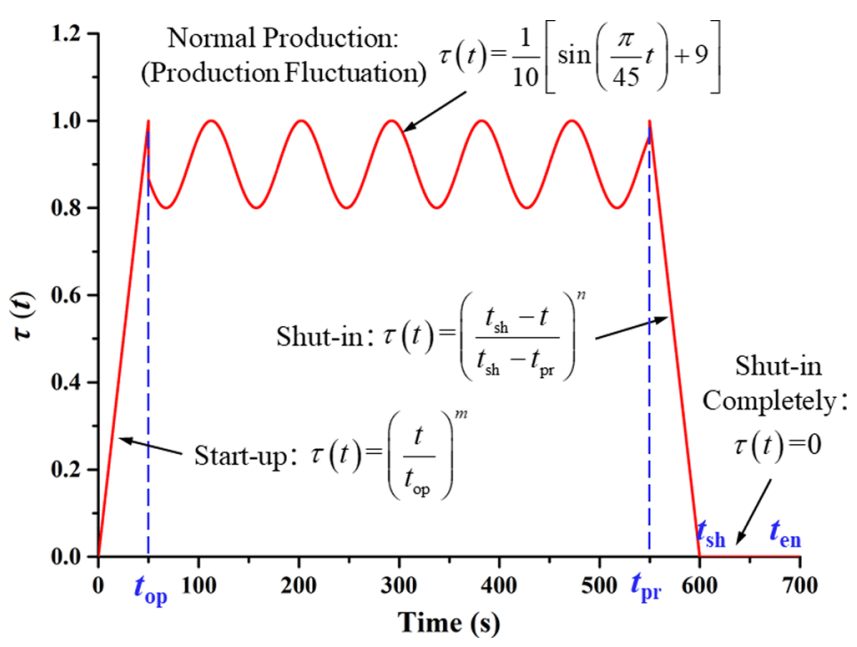

Fig. 3. Wellhead valve functions of gas well.

in the tubing string. There are many factors affecting the rule of production fluctuation, including some uncontrollable ones. Therefore, similar elementary functions can be used to describe the fluctuation form of production, so as to obtain the pressure fluctuation trend in the tubing during actual production.

If the valve function of production is assumed to be $\tau(t)$ during the complete production process of gas well, the wellhead valve operation can be described by the following piecewise function

$$
\tau(t)=\left\{\begin{array}{lr}
\left(\frac{t}{t_{\mathrm{op}}}\right)^{m}, & t \leq t_{\mathrm{op}} \\
f(t), & t_{\mathrm{op}} \leq t<t_{\mathrm{pr}} \\
\left(\frac{t_{\mathrm{sh}}-t}{t_{\mathrm{sh}}-t}\right)^{n}, & t_{\mathrm{pr}} \leq t<t_{\mathrm{sh}} \\
0, & t \leq t_{\mathrm{sh}}
\end{array}\right.
$$

wherein, $0 \sim t_{\mathrm{op}}$ is for valve opening stage, $t_{\mathrm{op}} \sim t_{\mathrm{pr}}$ for normal production stage, $t_{\mathrm{pr}} \sim t_{\mathrm{sh}}$ for valve closing stage and $t_{\mathrm{sh}} \sim t_{\mathrm{en}}$ for post-valve closing stage. The graph of valve functions is shown in Figure 3. 
Table 2. Physical and productive parameters.

\begin{tabular}{lclc}
\hline Parameter & Value & Parameter & Value \\
\hline Gas reservoir pressure, $\mathrm{MPa}$ & 74.93 & Relative density of natural gas & 0.583 \\
Gas reservoir temperature, ${ }^{\circ} \mathrm{C}$ & 142.8 & Outside diameter of tubing, mm & 88.9 \\
Average gas production, $10^{4} \mathrm{~m}^{3}$ day & 96 & Wall thickness of tubing, mm & 5.5 \\
Average water production, $\mathrm{m}^{3} /$ day & 9.5 & Well depth, $\mathrm{m}$ & 4875 \\
\hline
\end{tabular}

Table 3. The calculated value of the developed model are compared with the measured value.

\begin{tabular}{lcc}
\hline Item & The period of pressure fluctuation/s & Maximum fluctuating pressure $/ \mathrm{MPa}$ \\
\hline Measured value & 21.4 & 63.23 \\
Calculated value & 22.35 & 63.29 \\
Error & $4.44 \%$ & $-0.09 \%$ \\
\hline
\end{tabular}

\subsection{Model validation}

The reduction of production time and the simplification of production fluctuation, so the shut-in stage is selected to verify the model, and the calculation results were compared with the results in the reference to prove the accuracy of this model (Lin, 2017). The relative calculation parameters can be seen in Table 2 .

Transient shut-in will cause transient flow in the gas well, and the pressure fluctuation will appear near the wellhead and gas reservoir, which shows periodic change. The pressure fluctuation amplitude of wellhead is higher than that of bottom in the gas well. The maximum pressure difference of wellhead pressure wave is $0.6 \mathrm{MPa}$, and the fluctuation period is $21 \mathrm{~s}$.

The comparison results are shown in Table 3 and Figure 4. The results show that the absolute error between the maximum value of wellhead fluctuation pressure calculated by developed model and the measured value is only $0.09 \%$, and the error of pressure fluctuation period is $4.44 \%$. Compared with the calculation results in the literature, the peak value of the fluctuation pressure of the developed model is closer to the measured value, and the wellhead pressure fluctuation trend is more consistent. It can reflect the abnormal rise and fall of the pressure after shut-in and the transmission and attenuation of the pressure wave.

\section{Field application and discussion of results}

\subsection{Computational analysis}

Taking Well XX for an example, the pressure fluctuation situation in the tubing string of the well during the complete production process is simulated. It is assumed that the fluctuation of production follows a sine function according to the field production data curve of Well XX, and the specific form can be written as

$$
\tau(t)=\frac{1}{10}\left[\sin \left(\frac{\pi}{45} t\right)+9\right] .
$$

Set the opening and shut-in of Well XX as linear operations, namely $m=1, n=1$, the time function of wellhead valve $\tau(t)$ can be presented by equation (51).

$$
\tau(t)=\left\{\begin{array}{lr}
\frac{t}{t_{\mathrm{op}}}, & t<t_{\mathrm{op}} \\
\frac{1}{10}\left[\sin \left(\frac{\pi}{45} t\right)+9\right], & t_{\mathrm{op}} \leq t<t_{\mathrm{pr}} \\
\frac{t_{\mathrm{sh}}-t}{t_{\mathrm{sh}}-t} & t_{\mathrm{pr}} \leq t<t_{\mathrm{sh}} \\
0, & t \leq t_{\mathrm{sh}}
\end{array}\right.
$$

Manual calculation is not recommended due to huge amount of calculation of discrete equation of pressure fluctuation in tubing string of gas well during production. Instead, computer program will be used for simulating the progress. The model calculation flow chart is shown in Figure 5.

If the valve function is defined as one-dimensional array Tao ( ), the valve operation can be controlled by the following code

$$
\begin{aligned}
& \mathrm{M}=\operatorname{round}(\mathrm{T} / \mathrm{dt}) ; \quad \% \boldsymbol{T} \text { is the total calculation time; } \\
& \operatorname{TaO}(\mathrm{i})=\operatorname{zeros}(\mathrm{M}+1,1) \\
& \operatorname{Tao}(1)=0 ; \quad \% \text { The valve is fully closed at } \\
& \text { the initial moment; } \\
& \text { for } \mathrm{i}=2: \mathrm{M}+1 \quad \% \text { Cycle time: } \mathbf{i}=\mathbf{i}+\mathbf{1} \text {; } \\
& \text {...... \% Several procedures are omitted; } \\
& \mathrm{t}_{\mathrm{x}} \mathrm{x}=(\mathrm{i}-1)^{*} \mathrm{dt} ; \quad \text { \% Running time; } \\
& \left.\overline{\mathrm{Tao}}(\mathrm{i})=\left(\left(\mathrm{t} \_\mathrm{x} / \mathrm{t}_{-} \mathrm{op}\right)\right)^{\wedge} \mathrm{m}\right){ }^{*}\left(\mathrm{t}_{-} \mathrm{x}<\mathrm{t} \_\mathrm{op}\right)+\left(0.9+\mathrm{a}^{*} \sin \right. \\
& \left.\left(2^{*} \mathrm{pi}^{*} \mathrm{t} \quad \mathrm{x} / \mathrm{T}\right)\right) \cdot{ }^{*}(\mathrm{t} \quad \overline{\mathrm{x}}>=\mathrm{t} \text { op\&t } \mathrm{x}<\mathrm{t}-\mathrm{pr})+((1-(\mathrm{t} \quad \mathrm{x}- \\
& \left.\left.\left.\left.\mathrm{t} \_\mathrm{pr}\right) / \overline{(\mathrm{t}} \_\mathrm{sh}-\mathrm{t} \_\mathrm{pr}\right) \overline{)} \cdot{ }^{\wedge} \mathrm{n}\right) \cdot * \overline{(\mathrm{t}} \_\mathrm{x}>\overline{\bar{t}} \text { t_pr\&t_x }<\mathrm{t} \_\mathrm{sh}\right)+0 * \\
& \left(\mathrm{t}_{-} \mathrm{x}>=\mathrm{t}_{-} \mathrm{sh}\right) \text {; } \\
& \text {..... } \\
& \% \text { Valve piecewise function; } \\
& \% \text { Several procedures are omitted. }
\end{aligned}
$$

In this paper, a pressure fluctuation model of the complete production process (including well opening, 


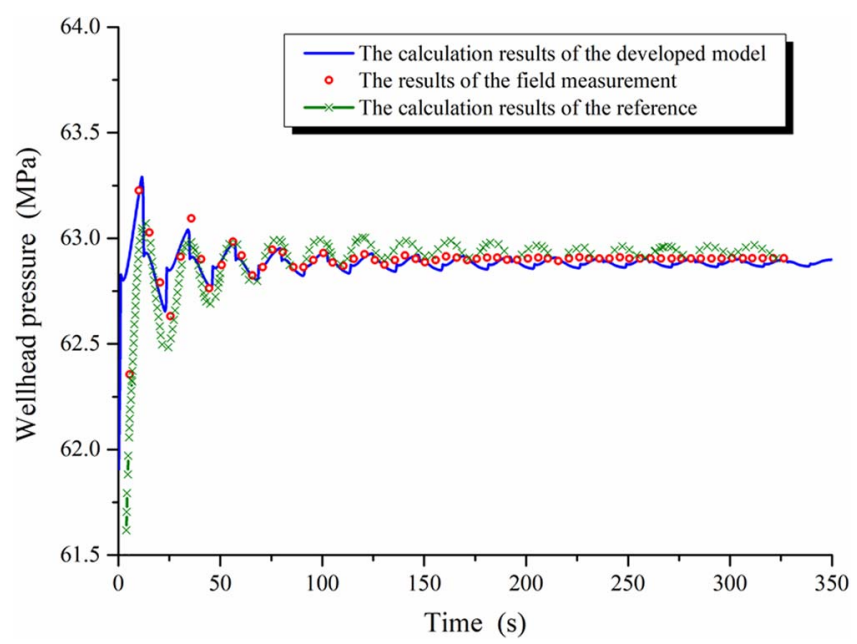

Fig. 4. The results of the developed model are compared with the field measurement and reference.

production and shut-in) is established, which is suitable for the multiphase flow of gas well. The pressure fluctuation in the tubing string is simulated. Influence of different well depth and average production on the fluctuating pressure of gas well are analyzed. The basic data of XX well is shown in Table 4.

\subsection{Discussion results}

Make the valve completely opened with the opening time of $50 \mathrm{~s}$ and valve opening coefficient of 1.0 (linear opening). After well opening completely, set the normal production time as $500 \mathrm{~s}$, then shut down the well with the valve closing time of $50 \mathrm{~s}$ and valve closing coefficient of 1.0 (linear shut-in). The pressure variation in tubing string of gas well during the production process can be obtained. Wherein, the fluctuation of wellhead pressure is shown in Figure 6, partially amplify the process of well opening and shut-in, as shown in Figures 7 and 8.

Before opening the valve, the fluid in tubing string is static. After opening, the wellhead fluid velocity starts to increase from 0 , wellhead pressure is released. The transient pressure fluctuation occurs and the pressure decreases gradually from shut-in static pressure.

After valve is completely opened, the valve function is changed into $\tau(t)$ in production stage. Due to the instantaneous change of the two valve functions, the wellhead pressure will fluctuate within 10 15 s after $50 \mathrm{~s}$ of well opening, but the fluctuation value is smaller and the attenuation is faster. During the production process of $t_{\mathrm{op}} \sim t_{\mathrm{pr}}$, the wellhead pressure fluctuating rule is similar with the fluctuating rule of corresponding valve function. When time reaches $t_{\mathrm{pr}}$, the well will be shut in and the valve function changes into $\tau$ $(t)$ in well shut-in stage. At the moment of valve closing, the wellhead speed changes to 0 all of a sudden, pressure increases quickly in the shut-in moment and reaches the peak (about $64 \mathrm{MPa}$ ) at $t_{\mathrm{sh}}$. Then fluctuating pressure propagates in the form of triangular wave, which will attenuate gradually under the effect of frictional resistance.

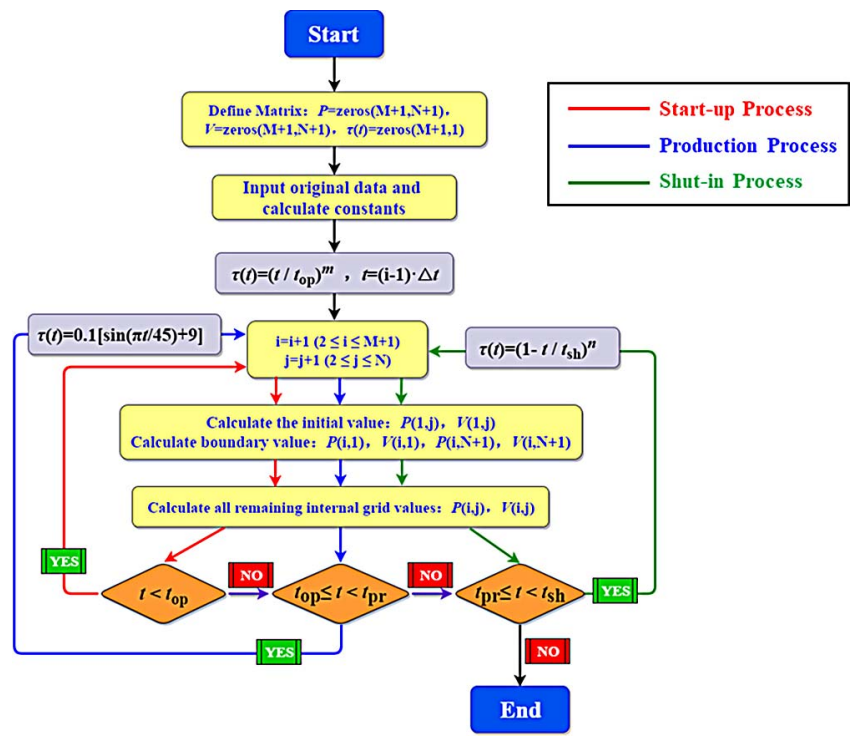

Fig. 5. Calculation flow chart of production process of gas well.

The calculation is set to stop (in order to greatly reduce the computing time, only a small part of production time is calculated) at the time of $t_{\mathrm{en}}=700 \mathrm{~s}$. If the calculation continues, the peak pressure will gradually decrease and the valley pressure will gradually increase. After a period of time, the peak value will coincide with the valley value and a balance will be reached.

The pressure fluctuation at different depths sof well is different. The pressure fluctuation at different depths of Well XX during the production is simulated in this paper, as shown in Figure 9. According to the calculation results, the pressure change trends at different depths of well are basically the same in different valve operation modes. From wellhead, pressure increases gradually with the well depth, but fluctuation flattens out. At the wellhead, the fluctuation amplitude of pressure during production is about $1 \mathrm{MPa}$, while at the well depth of $4200 \mathrm{~m}$, the fluctuation amplitude of pressure during production is only about $0.225 \mathrm{MPa}$. During well shut-in, the pressure at wellhead increases by about $2.75 \mathrm{MPa}$ quickly and the pressure at the depth of $4200 \mathrm{~m}$ only increases by about $0.65 \mathrm{MPa}$.

Figure 10 is the partially amplifying curve of well opening stage and pre-production stage. According to the curve, the pressure at wellhead changes all the time during well opening stage. With the increase of well depth, there is no obvious change of pressure in a short time (it is relatively remarkable at the depth of $4200 \mathrm{~m}$ ). When wellhead valve is opened, the fluid flow in tubing string is transient flow, short acting time of valve will result in water hammer effect and cause great fluctuating pressure. But why the pressure has little change? It is interesting. The reason is that pressure wave propagation requires time, valve acts at any time within the $50 \mathrm{~s}$ of well opening and the flowing of fluid at the nearest wellhead from valve changes at any time. But the pressure wave caused by fluid change needs to be propagated to the bottom of well through wellhead, and 
Table 4. Physical and production parameters of well XX.

\begin{tabular}{lclc}
\hline Parameter & Value & Parameter & Value \\
\hline Gas reservoir pressure, $\mathrm{MPa}$ & 97 & Gas reservoir temperature, ${ }^{\circ} \mathrm{C}$ & 124 \\
Wellhead flow pressure, $\mathrm{MPa}$ & 62 & Shut-in static pressure, MPa & 76 \\
Average gas production, $10^{4} \mathrm{~m}^{3} /$ day & 110 & Relative density of natural gas & 0.60 \\
Well depth, m & 5600 & Wall thickness of tubing, mm & 7.34 \\
Outside diameter of tubing, mm & 88.9 & Density of tubing, $\mathrm{kg} / \mathrm{m}^{3}$ & 7800 \\
Elastic modulus of tubing, GPa & 207 & Poisson's ratio of tubing & 0.30 \\
\hline
\end{tabular}

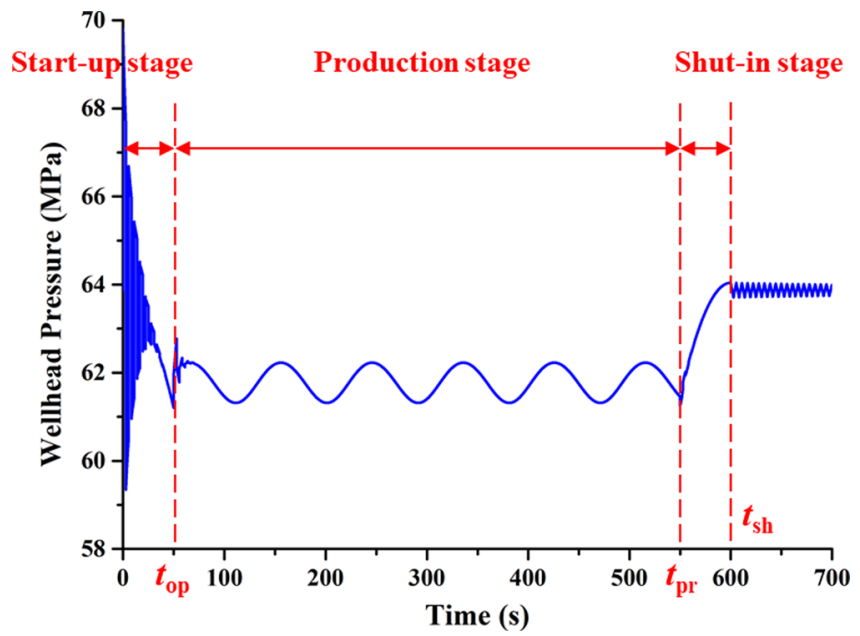

Fig. 6. Wellhead pressure fluctuation of gas well throughout production process.

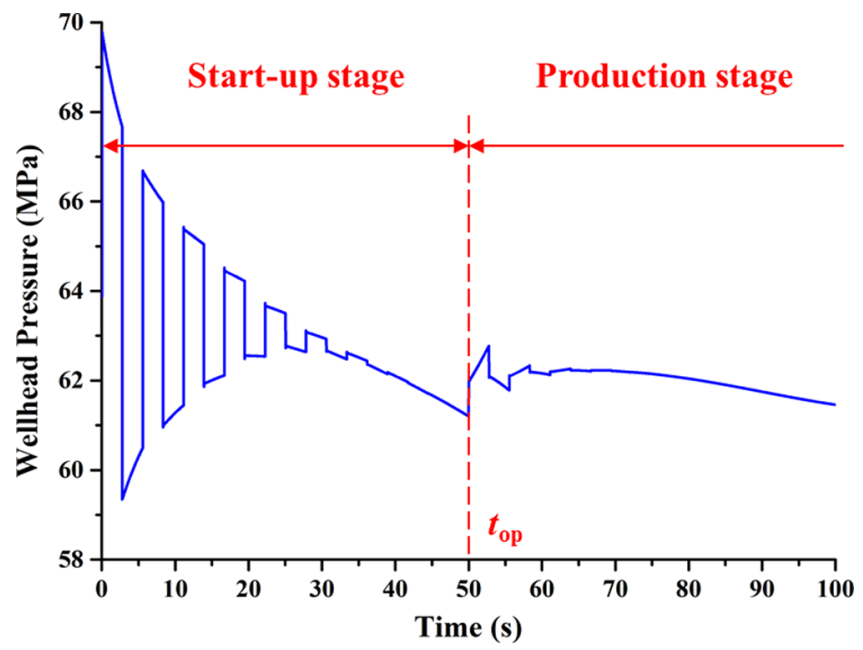

Fig. 7. Wellhead pressure fluctuation of gas well.

the propagation time increases along the depth. Before the pressure wave reaching the bottom, the fluid pressure in tubing string has little change.

At the end of well opening and the beginning of production, the valve function changes instantaneously, and the pressure in the tubing string fluctuates again. Similarly, wellhead pressure wave occurs when valve action is changed

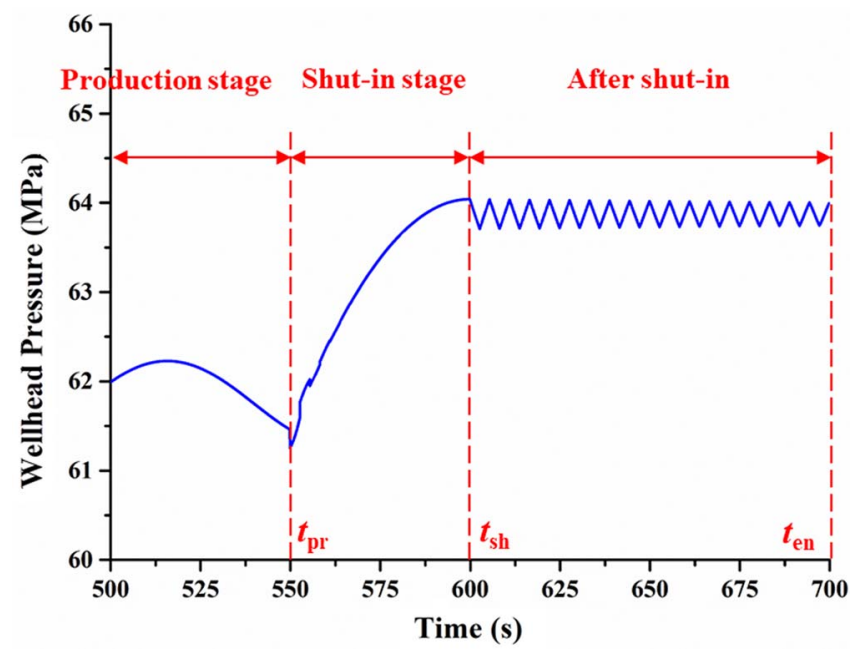

Fig. 8. Wellhead pressure fluctuation of gas well throughout production process (start-up part).

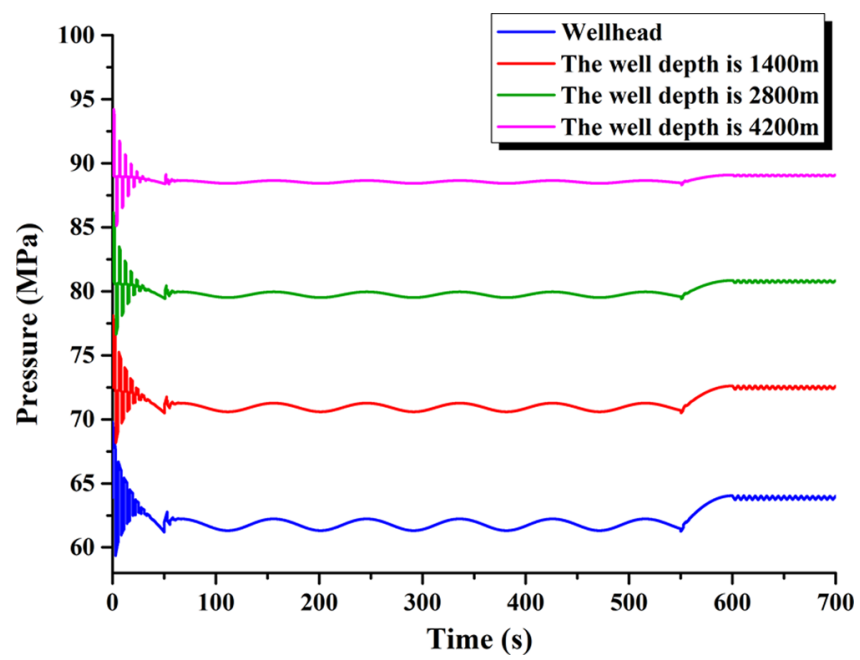

Fig. 9. Pressure fluctuation in different well depths throughout production process (shut-in part).

as wellhead is close to the valve. With the increase of well depth, the appearance time of pressure wave will lag obviously, as shown in the blue box of Figure 9. The deeper the gas well, the longer the hysteresis time of the pressure wave is and the smaller the corresponding fluctuating pressure is. 


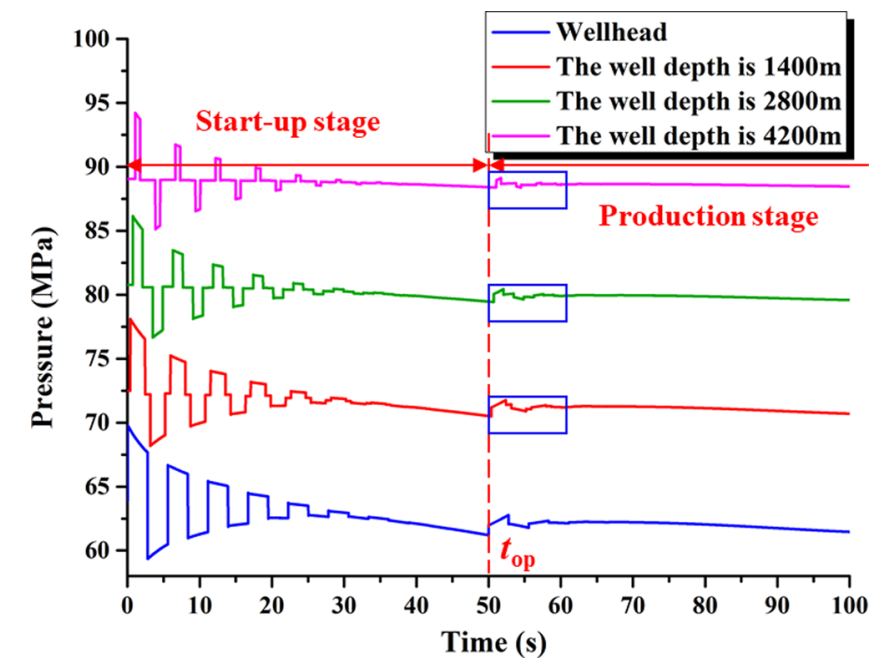

Fig. 10. Pressure fluctuation in different well depths during production during production (start-up part).

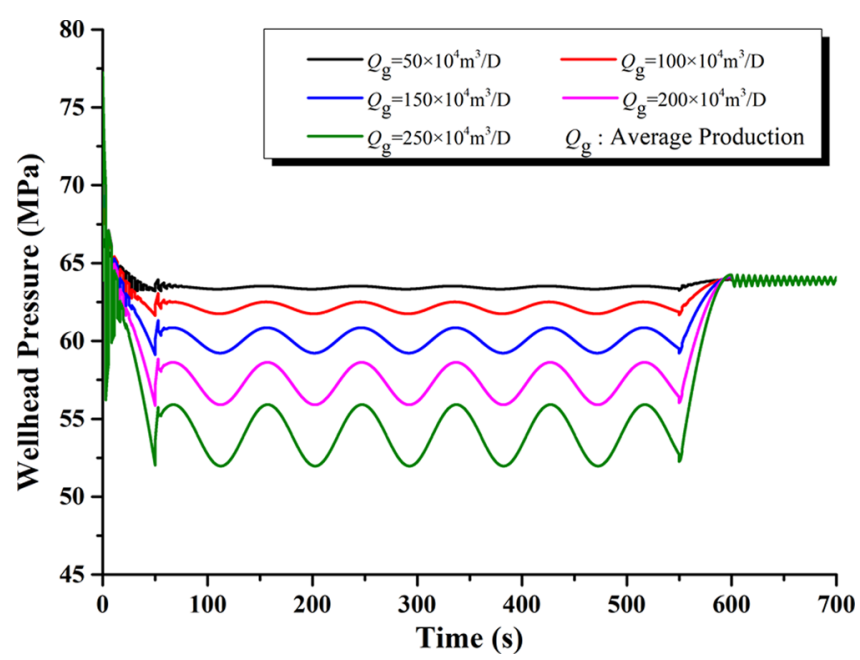

Fig. 11. Pressure fluctuation under different average productions throughout production process.

If pressure wave fails to be propagated to the specified depth for relatively great resistance caused by well depth, there will be no similar pressure fluctuation.

Production of gas well changes all the time. Different average productions may also lead to different pressure fluctuations of gas well. In this paper, the pressure fluctuation situations in tubing string throughout production under 5 average production conditions are simulated, as shown in Figure 11. In addition, the partially amplified figures of pressure fluctuation in well opening stage and well shut-in stage are provided, as shown in Figures 12 and 13.

According to the calculation results, the greater the average production of gas well, the greater the pressure fluctuation in tubing string during well opening and production, but pressure may not be very high. During well shut-in, the greater the production, the greater the pressure fluctuation and pressure value. According to Figure 13, if

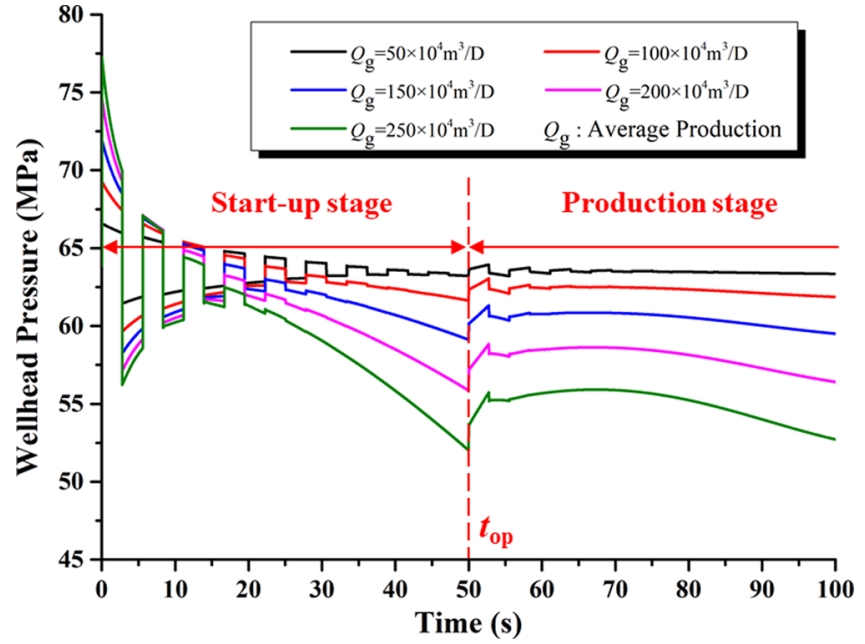

Fig. 12. Pressure fluctuation under different average productions (start-up stage).

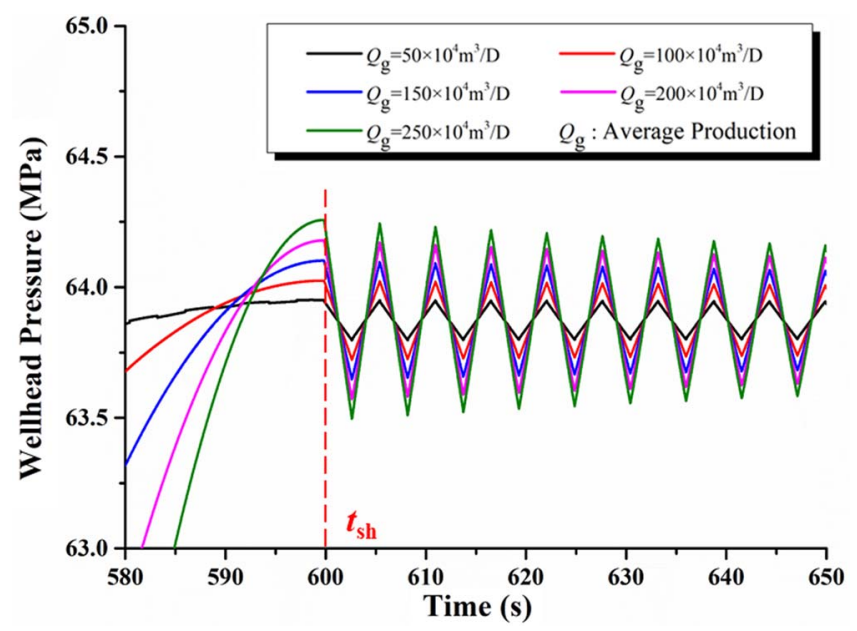

Fig. 13. Pressure fluctuation under different average productions (shut-in stage).

average production is $250 \times 10^{4} \mathrm{~m}^{3} / \mathrm{D}$, wellhead pressure rises to $64.25 \mathrm{MPa}$ after well shut-in, pressure value and fluctuation amplitude exceed the working conditions under other average production.

The reasons for this phenomenon are as follows: shut in is to seal the flow section during the process of high-speed fluid flow in the tubing string, so that the high-speed fluid becomes static in a short time. Therefore, the higher the average production, the faster the flow rate, and the higher the pressure when the flow rate becomes 0 .

During production of gas well, the pressure fluctuation situation in tubing string changes accordingly with the varying valve functions and production. After making appropriate deformation on the valve functions during production, it is not difficult to see that the valve operation meets the standard fluctuation function, as shown in equation (52). 


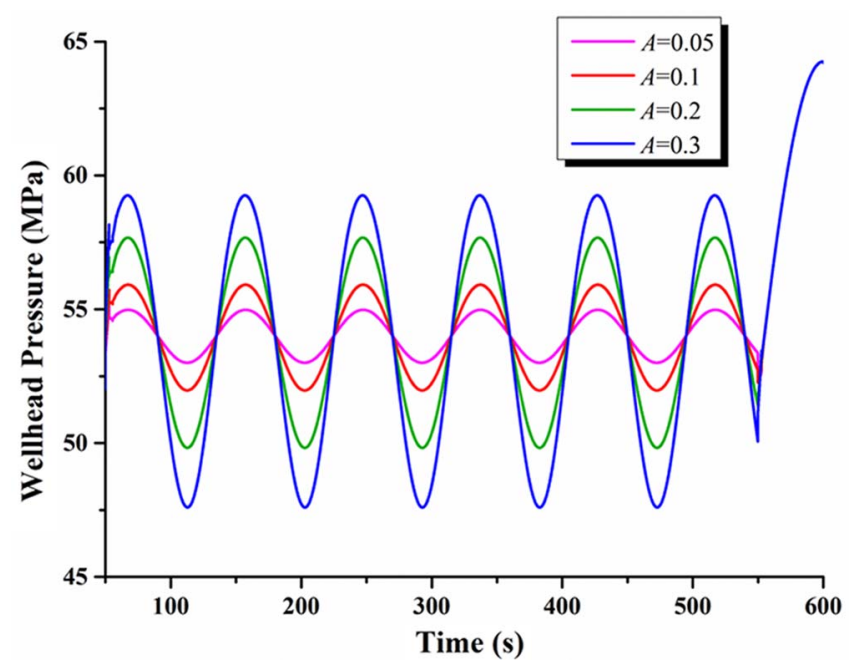

Fig. 14. Pressure fluctuation in tubing under different amplitudes $A$.

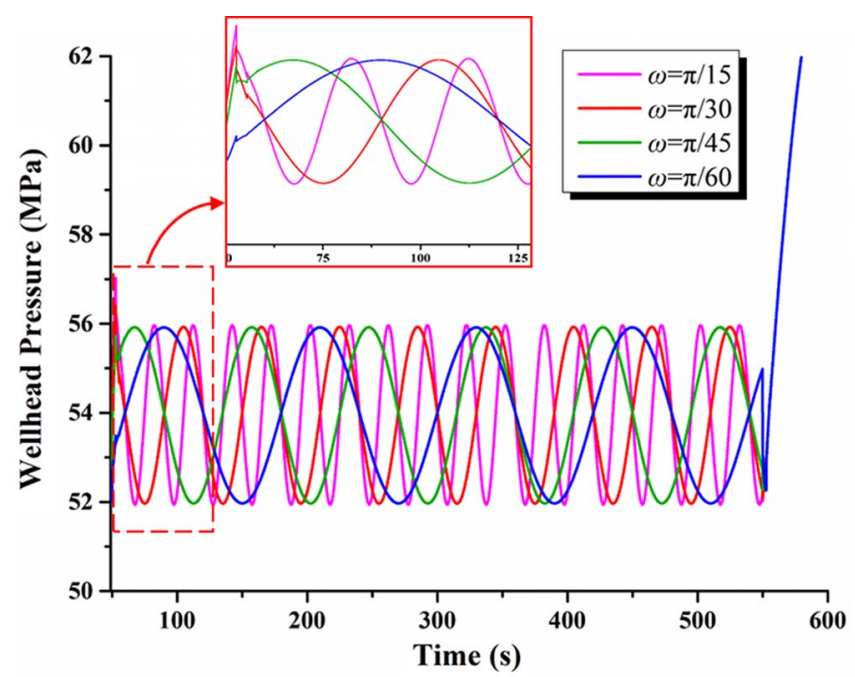

Fig. 15. Pressure fluctuation in tubing at different angular frequencies $\omega$.

$$
\tau(t)=A \sin (\omega t+\varphi)+B .
$$

wherein, $A$ is fluctuation amplitude, $\omega$ is fluctuation angular frequency, $\varphi$ is phase angle and $B$ is valve radix. In the valve functions assumed based on an actually measured production data of Well XX, it is observed that $A=0.1, \omega=\pi / 45, \varphi=0$ and $B=0.9$. The value of fluctuation amplitude and angular frequency may affect the overall operation of valve, and then affect the pressure fluctuation in tubing string. In this paper, the influence of four standard fluctuation parameters on pressure in tubing string is studied by control variate method, the calculation results are shown in Figures 14-17.

Amplitude, angular frequency and phase angle are parameters of triangular wave function in valve functions, which directly affect the vibration mode of triangular wave function image, while the fluctuating rule of triangular

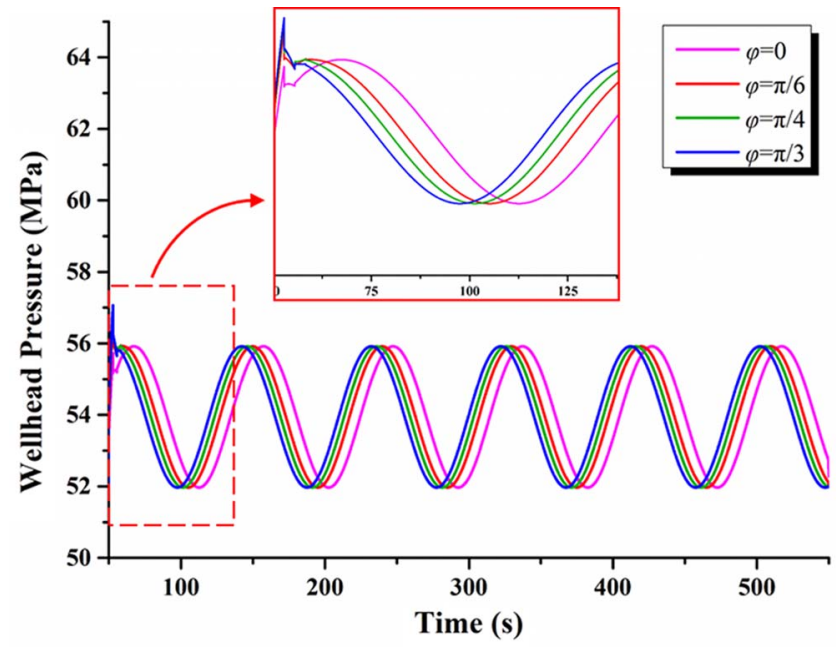

Fig. 16. Pressure fluctuation in tubing at different phase angles $\varphi$.

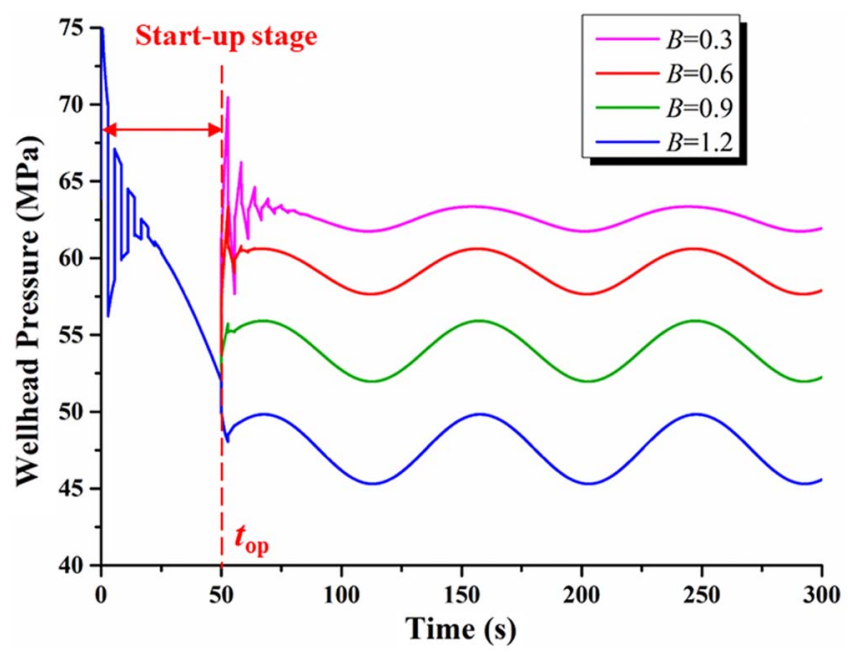

Fig. 17. Pressure fluctuation in tubing under different valve radix $B$.

wave function reflects the pressure fluctuating rule to a great extent. When Amplitude $A$ of valve function changes, the greater the amplitude, the greater change in fluid flow rate in tubing string and the more obvious the pressure fluctuation. In actual production, reducing amplitude of valve function is the most effective way to prevent wellhead water hammer phenomenon.

Angular frequency $\omega$ indicates the number of wavelengths of triangular wave propagated in unit time. The greater the angular frequency, the shorter the cycle of triangular wave and the more the wavelengths propagated. In this way, the frequency of fluid velocity change in the tubing string will be accelerated, and the pressure fluctuation will be more obvious. When the angular frequency is low, the frequency of fluid velocity changes in the tubing string decreases, and the pressure fluctuation is smoother than the former. 
The greater the phase angle $\varphi$, the greater the pressure extreme value generated when valve function changes and the more advanced the fluctuation time is. The smaller the phase angle, the smaller the pressure extreme value and the later the fluctuation time is. However, during production, the phase angle value would not affect the form of pressure wave, which means that the fluctuation peak value, valley value and cycle would not change along with the phase angle value. Therefore, phase angle has little influence on the pressure fluctuation in tubing string in principle.

Valve radix $B$ is the only one among the four standard parameters of valve function not belonging to triangular wave function, which is in algebraic relation with triangular wave. The greater the valve radix, the greater the valve function value. Valve function indicates the opening of valve. The greater the opening, the greater the overflow section of fluid and the smaller the pressure. When valve function changes, the pressure wave extreme value is relatively small. The smaller the valve radix, the smaller the valve opening, the smaller the overflow section of fluid and the pressure is relatively large. As shown in Figure 16, taking $B=0.3$ as an example. When the valve function changes, a large extreme value of pressure wave will be generated near the top. However, when the extreme value of pressure wave decays, the amplitude of pressure wave will gradually flatten, which is smaller than the working condition when the valve radix is large.

\section{Conclusion}

In this paper, aiming at the problem of transient pressure fluctuation in tubing string caused by production fluctuation and a pressure fluctuation model of the complete production process (including well opening, production and shut-in) is established, which is suitable for the multiphase flow of gas well. The pressure fluctuation in the tubing string is simulated. Influence of different well depth and average production on the fluctuating pressure of gas well are analyzed. The main conclusions are as follows:

1. After well opening, the transient pressure fluctuation occurs and the pressure decreases gradually from shut-in static pressure. The wellhead pressure will fluctuate within 10 15 s after 50 s of well opening, but the fluctuation value is smaller and the attenuation is faster. At the moment of valve closing, the wellhead pressure increases quickly in the shut-in moment and reaches the peak at $t_{\mathrm{sh}}$.

2. After well opening, pressure increases gradually with the well depth, but fluctuation flattens out. At the beginning of production, the pressure in the tubing string fluctuates again. With the increase of well depth, the appearance time of pressure wave will lag obviously.

3. The greater the average production of gas well, the greater the pressure fluctuation in tubing string during well opening and production, but pressure may not be very high. During well shut-in, the greater the production, the greater the pressure fluctuation and the greater the pressure.
4. In valve function, the greater the Amplitude $A$ and angular frequency $\omega$, the greater change in fluid flow rate in tubing string and the more obvious the pressure fluctuation. The greater the phase angle $\varphi$, the greater the pressure extreme value generated when valve function changes and the more advanced the fluctuation time is. The greater the valve radix $B$, the greater the valve function and the smaller the pressure.

Acknowledgments. The authors are grateful for the support of the National Natural Science Foundation of China (Grant No. 52074234), Innovative Research Team of Sichuan Province (2020JDTD0016), Major scientific and technological projects of CNOOC (China) Co., Ltd (CNOOC-KJ 135 ZDXM 38 ZJ 05 ZJ)

\section{References}

Adiputro A.S., Zarrouk S.J., Clarke R.J., Harcout-Menou V., Bos S. (2020) Geothermal wells with water hammer during injection fall-off test: Numerical pressure transient analysis, Geothermics 87, 101838.

Alexander A. (1976) Menabrea's Note on Water Hammer:1858. J. Hydr. Div. 102, 1, 29-39.

Allievi L. (1925) The Theory of Water Hammer. Translated by Halmos E.E.. Riccardo Garoni, Rome, Italy.

Assaad W., Crescenzo D.D., Murphy D., Boyd J. (2019) Computation of surge pressure wave propagation during cementation process, SPE Drill. Complet. 351, 114-124.

Bojan I., Stevanovic V.D., Aleksandar G. (2018) Water hammer with non-equilibrium gas release, Int. J. Pressure Vessels Pip 165, 229-240.

Fang Q., Meng Y.F., Li H.T., Wei N., Li G. (2019) Transient pressure fluctuation effect during gas drilling in horizontal well, Chem. Tech. Fuels Oils 55, 4, 497-507.

Han G.Q., Ling K.G., Khor S.H., Zhang H., Company R.S., Thakur R.K. (2012) Simulation of multiphase fluid-hammer effects during well shut-in and opening, in: SPE Asia Pacific Oil and Gas Conference and Exhibition, Perth, Australia.

Jin Y., Chen K.P., Chen M., Grapsas N., Zhang F.X. (2011) Short-time pressure response during the start-up of a constantrate production of a high pressure gas well, Phys. Fluids 23, 4 .

Joukowsky N. (1904). Waterhammer. Translated by Simin O., Proc. Amer. Water Works Assoc., 24, 341-424.

Li H.Y., Zhang Z., Zhang J.W., Zhang H.W. (2013) The impact of changes in the high-yield gas well production on tubing string vibration, J. Chongqing Univ. Sci. Technol. (Nat. Sci. Ed.) 15, 6, 28-30, 34 .

Lin C. (2017) Establishment and solution of the mathematical model of multiphase water hammer in gas wells, Acta Pet. Sin. 38, 7, 813-820.

Lin C., Zhang X., Liu S.M., Zhou S.L., Lan Q., Chen Q. (2018) Development and application of water hammer wave velocity calculation chart of wellbore gas-liquid two-phase flow, $J$. Xian Pet. Univ. (Nat. Sci. Ed.) 33, 1, 79-84.

Mou Y.S., Lian Z.H., Sang P.F., Yu H., Zhang Q., Li R. (2019) Study on water hammer effect on defective tubing failure in high pressure deep gas well, Eng. Fail. Anal. 106, 104154.

Ogunyemi E.O., Oghenewoakpo S. (2019) Well control: Hard or soft shut-in, the onshore experience, in: SPE Nigeria Annual International Conference and Exhibition, Lagos, Nigeria.

Sun C.Y., Li S.Z., Xu N. (2019) PML and CFS-PML boundary conditions for a mesh-free finite difference solution of the elastic wave equation, Appl. Geophys. 164, 438-454. 
Wu X.Z., Wan F.L., Chen Z., Han L.X., Li Z.L. (2020) Drilling and completion technologies for deep carbonate rocks in the Sichuan Basin: Practices and prospects, Nat. Gas Ind. 7, 5, $547-556$.

Wylie E.B., Streeter V.L. (1983) Transient flow, Water Resources and Electric Power Press, Beijing.

Zhang Z., Li Y.J., Zhang C., Huang Y., Guo Y.B., Luo L.M., Shi T.H. (2013) Wellbore integrity design of high-temperature gas wells containing $\mathrm{CO}_{2}$, Nat. Gas Ind. 33, 9, 79-86.

Zhang Z., Shao L.Y., Zhang Q.S., Zhang C., Li J., Zeng D.Z., Zhong X.K., Hu J.Y., Hou D., Shi T.H. (2017a) Environmentally assisted cracking performance research on casing for sour gas wells, J. Pet. Sci. Eng. 158, 729-738.

Zhang Z., He Y., Huang X., He H.P., Bao H.Z. (2017b) Research on prediction of integrity risk grade of sour gas well, China Saf. Sci. J. 27, 10, 155-161.
Zhang Z., Li J., Zheng Y.S., Zhang C., Zhang Q.S., Zeng D.Z., Zhong X.K. (2018) Finite service life evaluation method of production casing for sour-gas wells, J. Pet. Sci. Eng. 165, 171-180.

Zhang Z., Wang J.W., Luo M., Li Y.J., Zhang W.D., Wu J., Li W.T. (2020a) Effect of instantaneous shut-in on well bore integrity and safety of gas wells, J. Pet. Sci. Eng. 193, 107323.

Zhang Z., Sang P.F., Sang Z.P., Hou D., Zhang C. (2020b) Analyzing failure of casing head slip hanger, Eng. Fail. Anal. 108, 104301.

Zhang Z., Wang J.W., Li Y.J., Luo M., Zhang C. (2020c) Effects of instantaneous shut-in of high production gas well on fluid flow in tubing, Pet. Explor. Dev. 473, 642-650.

Zhang Z., Zheng Y.S., Li J., Liu W.Y., Liu M.Q., Gao W.X., Shi T.H. (2019) Stress corrosion crack evaluation of super $13 \mathrm{Cr}$ tubing in high-temperature and high-pressure gas wells, Eng. Fail. Anal. 95, 263-272. 